selected bibliography, and the classification of each group more comprehensively than in some standard student textbooks. Dissection instructions are somewhat general in the hope that they may be of use for different species. Indeed, the choice of examples has been guided by practical supply in an attempt to make the book of use through out the world. A number of small errors will no doubt be corrected in future editions.

Changing emphasis in biology tends to reduce the time available for study of the functional morphology of invertebrates; but this book should stimulate interest, not least by the ideas put forward for experiments to be carried out in association with the more traditional dissections. Within the framework of courses on invertebrate biology every opportunity should be taken to bring the student into contact with the living animal both by direct observations and by use of ciné film.

This practical guide has been designed to meet the needs of the student in the laboratory and to act as a source for the teacher. It is as a laboratory manual used in conjunction with a standard textbook that this book is to be recommended to teachers of invertebrate zoology.

E. R. Trueman

\section{BONES OF REPTILES}

\section{Biology of the Reptilia}

Edited by Carl Gans. Vol. 1: Morphology A. Edited by Angus d'A. Bellairs and Thomas S. Parsons. Pp. xv +373. (Academic Press: London and New York, February 1969.) $80 s ; \$ 11.50$.

THE tempo of study of the biology of the reptiles has quickened greatly in recent years. Monographs, some of excellent quality, now cover areas for which no overall summaries are available. Other existing monographs are badly out of date. In view of these gaps, the series entitled Biology of the Reptilia under the general editorship of Carl Gans is a very welcome addition to the literature on reptilian biology. The major goal of this continuing series is to furnish broad, yet detailed, surveys on the morphology, embryology, physiology, ecology and ethology of the reptiles.

This first volume of the series deals with the origin of reptiles, the reptilian bone as a tissue, epiphyses and sesamoids, dentition, vertebrae and ribs, and the turtle shell.

The chapter on the origin of reptiles serves as a relatively brief but adequate introduction to the prehistory of the major groups of Recent reptiles. It seems to have been written for the non-specialist. The justification for inclusion of such a chapter in a series meant for the specialist is debatable. The accompanying bibliography is, however, extensive and will facilitate future work. The contribution on reptilian bone tissue is very original and furnishes numerous previously unpublished figures. Important information can be found on the evolution of reptilian bone, the significance of cortical stratification and non-vascular bone. The discussion on epiphyses and sesamoids is illustrated with thirty-nine excellent figures that have not been published previously. Strong evidence is given for the complete independence of sesamoids, apophyseal and epiphyseal centres. The chapter on dentition represents the most complete, penetrating and meaningful review available to date on reptilian odontology. Much of the discussion on teeth is based on an exhaustive analysis of the literature. Although there is emphasis on teeth of Recent reptiles, some fossil forms are discussed. The review of vertebrae and ribs of modern reptiles emphasizes the seemingly endless variation in the structural pattern of the axial skeleton, which reflects the heterogeneity of the class. The 190 references on vertebrae and ribs are a good indication of the thoroughness with which this review has been prepared. In the final con- tribution, the turtle shell is discussed biologically, and it is stressed that the presumed uniformity of the turtle shell has been greatly overstated. The elegant analysis of the osteogenesis of the dermal bones and of the morphogenetic controls that determine the bone and shield patterns of the turtlo shell represents the theme of Biology of the Reptilia. "Our aim is to facilitato future work rather than place a tombstone upon past knowledge."

This volume is without doubt an example of exceptional scholarship and great versatility. This continuing series will undoubtedly be the most important addition to the literature on reptilian biology in the past decade and one in which both editor and publisher may justifiably have great pride.

K. F. LIFM

\section{PHYSIOLOGY OF INSECTS}

\section{The Insects}

Structure and Function. By R. F. Chapman. (Biological Science Texts.) Pp. xii +819 . (English Universities Press: London, September 1969.) $85 s$.

There have been several large composite works on the physiology of insects published during the past twenty years; works in which different specialists survey the more or less restricted territory of their speciality. Valuable though such books can be, they are always full of gaps and they lack coherent presentation; and physiology is nothing if it is not coherent. It is therefore a mattor of great interest to entomologists of all kinds that a new single-author book dealing with the entire field should have appeared.

Dr Chapman's impressive book is a large one, with more than 800 pages each measuring $7 \times 10$ inches and furnished with more than 1,000 references and 500 textfigures. The first thing that strikes the reader is the imaginative way in which it is organized. The sequence of presentation is original but logical. Consideration of the structure of the head leads to the study of feeding and digestion, nutrition and motabolism. Description of the thorax, with the legs and wings, demands a full account of locomotion on land, in water and in flight, and of the muscles that provide the motive power. Likewise, the structure of the abdomen loads on to reproduction in all its aspects and hence to embryology, hatching, postembryonic development and metamorphosis; and so on, via the nervous system, sense organs and hormones, to conclude with a chapter on communication through pheromones. Each of the thirty-six chapters begins with a clear and simple summary, half a page or so in length, and a list of recent specialized reviews which cover its subject matter. This is followed by the detailed exposition, which varies somewhat in depth in different topics but is always adequate and often deals extensively with very recent work. The quality of the chapters naturally varies, but, taking the book as a whole, they reach a high standard of comprehensiveness and accuracy. It will therefore be of great value not only as an introduction to the specialized literature, but for the vast stores of information contained in its pages. The sections which deal with the physiology of locusts are particularly good, this being the field in which the author has had most first-hand experience.

This is the sort of book that invites praise and gratitude and not adverse criticism. But it has certain. characteristics, good or bad according to taste, to which attention may be drawn. It lacks a historical sense: it presents the picture as it exists today and there is no indication of where all this basic knowledge came from. Almost the only continental authors, even recent authors, whose work receives mention are those who have published reviews in English or American journals. It is very generously illustrated with large clear pictures, directly 